\title{
Empowering Residents to Address Socioeconomic Disparities in Dermatology
}

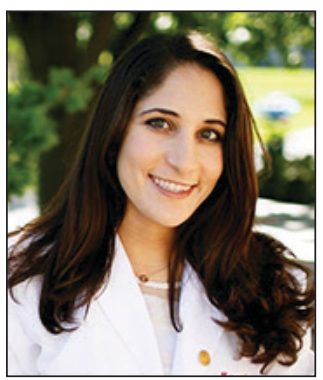

Soraya Azzawi, MD

\section{RESIDENT PEARL}

- Even while in training, dermatology residents have the agency to impact their communities by connecting their expertise to the patients in greatest need.
Vulnerable communities are in tremendous need of specialized dermatologic care. Through exposure to unique patient populations during medical school curricula and residency training, creation of partnerships with existing advocacy networks, and technological innovation, dermatology residents can harness their skill set to aid marginalized communities.

Cutis. 2021;107:E43-E45. couldn't help but wonder about the alternative outcomes to his case. Left untreated, scabies compromises the skin barrier, paving the way for secondary infections such as cellulitis. Depending on the pathogen, this infection may in turn evolve into acute postinfectious glomerulonephritis. ${ }^{1-4}$ An elusive diagnosis can quietly escalate into considerable morbidity for patients. This case highlights the dire consequences of dermatologic health disparities and places medicine's primordial function into sharp focus: the alleviation of suffering.

\section{The Dermatologic Burden of Disease}

As a major contributor to global disease burden, dermatologic disease is the fourth greatest cause of disability worldwide when mortality is factored out. ${ }^{5,6}$ Among global rural populations, dermatologic disease constitutes one of the leading causes of death and/or loss of professional capabilities. ${ }^{7}$ In the United States alone, nearly $27 \%$ of the population saw a physician for at least 1 dermatologic disease in $2013 .^{5}$ The tremendous prevalence of skin disease magnifies discrepancies in access to dermatologic care, which has been observed to be influenced by age, socioeconomic background, rurality, and sex. ${ }^{8}$

There has been growing focus on the national shortage of dermatologists over the last 2 decades., ${ }^{9,10}$ With an aging population and rising incidence of skin cancer, this undersupply is projected to increase and disproportionately impact ethnic minorities as well as those from socioeconomically disadvantaged backgrounds..$^{8,9,11-14}$ These trends are of particular importance to residents and medical trainees. Multiple studies have demonstrated that the patient demographic of hospital-based resident clinics

From the Department of Dermatology, University of Miami/Jackson Memorial Hospital, Florida.

The author reports no conflict of interest.

Correspondence: Soraya Azzawi, MD (swazzawi@gmail.com).

doi:10.12788/cutis.0234 
includes primarily minority and disenfranchised populations with poorer overall health. ${ }^{15-17}$ In contrast to faculty clinics, residents treat patients who are more likely to be nonwhite and more likely to be reimbursed by Medicaid. ${ }^{18}$ The unique demographic makeup of hospital-based resident clinics raises questions about the preparedness and comfort of resident physicians in managing the nuances of health care delivery in these settings. ${ }^{10}$

Providing equitable care to marginalized populations within the constraints of 15 - to 30 -minute visits can be challenging to physicians and trainees. Even clinicians with the best of intentions may be impeded by a lack of familiarity with the daily realities of impoverished living conditions, implicit prejudice against people living in poverty, and adapting recommendations to varying levels of health literacy among patients. ${ }^{19,20}$ Contending with these daunting obstacles can be discouraging. Given how entrenched certain institutional barriers are, questioning them may seem an exercise in futility, yet history demonstrates that residents can and have been empowered to improve tangible outcomes for vulnerable populations. In reflecting on approaches of the general medical education system, The Josiah Macy Jr. Foundation President George E. Thibault, MD, observed that, "When appropriately trained, deployed and incented, [residents] can help achieve institutional goals to improve quality, safety and efficiency."21

\section{Start Small But Dream Big}

Action begins with awareness. Medical school and teaching hospital curricula are increasingly integrating educational exercises regarding the social determinants of health and populations with unmet needs. Medical training presents an exclusive opportunity to gain exposure to and familiarity with patient populations that one might not otherwise encounter. Immersion programs provide invaluable experience in tailoring health care delivery to the needs of vulnerable communities. Although opportunities for international rotations abound, domestic rotations among underserved populations can be just as transformative, including correctional medicine, homeless clinics, the Indian Health Service, and rural communities.

\section{Create Partnerships to Broaden Impact of Service}

Affecting the largest and most visible organ, skin disease often presents a substantial concern for patients and can herald systemic disease. The nature of dermatologic disease engenders close collaboration between general practitioners and specialists. For example, while resident-run or safety-net clinics characteristically center on providing holistic care for patients through internal medicine or primary care, these overworked and understaffed clinics often are in need of evaluation by specialists for specific concerns. Some clinic models feature dermatology faculty who volunteer routinely (ie, every 2 weeks, every month) to examine all the clinic's patients presenting with concerns pertinent to the specialty. Drawing on their respective areas of expertise, general practitioners and dermatologists therefore can collaborate to connect disadvantaged patients with the specialized care they need.

\section{Challenges Present Opportunities for Innovation}

Adhering to the social distancing requirements of the COVID-19 pandemic protocol has driven clinicians to utilize innovative approaches to patient care. The ruralurban misdistribution of the dermatologist workforce has long been established, with rural patients often experiencing lengthy wait times to see a specialist. ${ }^{9}$ Both synchronous and asynchronous teledermatology modalities provide an ideal platform for triaging patients with dermatologic concerns who otherwise have meager access to a dermatologist.

\section{Final Thoughts}

Residency training is a prime opportunity to gain exposure to the broad spectrum of disease within dermatology as well as the diverse range of affected patients. Drawing on the aforementioned strategies, residents can leverage this knowledge in the service of underserved patients.

\section{REFERENCES}

1. McCarthy JS, Kemp DJ, Walton SF, et al. Scabies: more than just an irritation. Postgrad Med J. 2004;80:382-387.

2. Svartman M, Finklea JF, Earle DP, et al. Epidemic scabies and acute glomerulonephritis in Trinidad. Lancet. 1972;1:249-251.

3. Hersch C. Acute glomerulonephritis due to skin disease, with special reference to scabies. S Afr Med J. 1967;41:29-34.

4 Carapetis JR, Connors C, Yarmirr D, et al. Success of a scabies control program in an Australian aboriginal community. Pediatr Infect Dis J. 1997;16:494-499.

5. Lim HW, Collins SAB, Resneck JS Jr, et al. The burden of skin disease in the United States [published online March 1, 2017]. J Am Acad Dermatol. 2017;76:958-972.e2.

6. Karimkhani C, Dellavalle RP, Coffeng LE, et al. Global skin disease morbidity and mortality: an update from the Global Burden of Disease Study 2013. JAMA Dermatol. 2017;153:406-412.

7. Morrone A. Poverty, dignity, and forgotten skin care: dermatology in the stream of human mobile population. Dermatol Clin. 2008; 26:245-256, vi-vii.

8. Tripathi R, Knusel KD, Ezaldein $\mathrm{HH}$, et al. Association of demographic and socioeconomic characteristics with differences in use of outpatient dermatology services in the United States. JAMA Dermatol. 2018;154:1286-1291.

9. Feng H, Berk-Krauss J, Feng PW, et al. Comparison of dermatologist density between urban and rural counties in the United States. JAMA Dermatol. 2018;154:1265-1271.

10. Blanco G, Vasquez R, Nezafati $K$, et al. How residency programs can foster practice for the underserved. J Am Acad Dermatol. 2012; 67:158-159.

11. Kosmadaki MG, Gilchrest BA. The demographics of aging in the United States: implications for dermatology. Arch Dermatol. 2002;138:1427-1428.

12. Donaldson MR, Coldiron BM. No end in sight: the skin cancer epidemic continues. Semin Cutan Med Surg. 2011;30:3-5.

13. Dall TM, Gallo PD, Chakrabarti R, et al. An aging population and growing disease burden will require a large and specialized health care workforce by 2025. Health Aff (Millwood). 2013; 32:2013-2020.

14. Sauaia A, Dellavalle RP. Health care inequities: an introduction for dermatology providers. Dermatol Clin. 2009;27:103-107. 
15. Brook RH, Fink A, Kosecoff J, et al. Educating physicians and treating patients in the ambulatory setting. where are we going and how will we know when we arrive? Ann Intern Med. 1987;107:392-398.

16. Yancy WS Jr, Macpherson DS, Hanusa BH, et al. Patient satisfaction in resident and attending ambulatory care clinics. J Gen Intern Med. 2001;16:755-762.

17. Fiebach NH, Wong JG. Taking care of patients in resident clinics: where do we stand? J Gen Intern Med. 2001;16:787-789.

18. Loignon C, Boudreault-Fournier A, Truchon K, et al. Medical residents reflect on their prejudices toward poverty: a photovoice training project. BMC Med Educ. 2014;14:1050.
19. Scheid D, Logue E, Gilchrist VJ, et al. Do we practice what we preach? comparing the patients of faculty and residents. Fam Med. 1995;27:519-524.

20. Loignon C, Gottin T, Dupéré S, et al. General practitioners' perspective on poverty: a qualitative study in Montreal, Canada. Fam Pract. 2018;35:105-110.

21. Parks T. Empowered residents can help transform medical care. American Medical Association website. Published November 30, 2016. Accessed March 18, 2021. www.ama-assn.org/education/improve-gme/empowered-residents -can-help-transform-medical-care 